\title{
Perspectives: Other ErbB2-Targeted Therapies
}

\author{
Ulrike Nitz \\ Brustzentrum Niederrhein, Evangelisches Bethesda-Krankenhaus, Mönchengladbach, Germany
}

\section{Key Words}

Neratinib · Pertuzumab - Trastuzumab DM-1 .

ErbB dimerization inhibitor - Multifunctional tyrosine kinase inhibitors · ErB2 antibody-drug conjugate therapy

\section{Summary}

Despite the success of individualized targeted therapies in women with breast cancer with current available compounds, new drugs - especially with different mechanisms of resistance - are under development. A range of novel targeted agents for women with tumors that overexpress ErbB2 (HER2) and progress on trastuzumab and lapatinib have entered clinical studies. Most of these agents are monoclonal antibodies or multifunctional tyrosine kinase inhibitors. Recently published data even showed encouraging synergistic effects of several new substances, which in the future could pose as a chemotherapy-free treatment option in the metastatic setting.

\section{Neratinib}

Currently, the two most commonly employed strategies to overcome resistance and to improve clinical outcome are introducing covalent, and therefore permanent, irreversible binding of the drug to the target as well as blocking multiple signaling pathways within the cell avoiding the emergence of resistant cell clones that bypass the inhibited receptor [1]. Neratinib (HKI-272) is an orally administered dual inhibitor of the ErbB2 (HER2) and ErbB1 kinase, using both the strategies of irreversible binding and multitargeting [2]. Neratinib interacts directly with its target enzyme and forms a covalent

\section{Schlüsselwörter}

Neratinib · Pertuzumab - Trastuzumab DM-1 .

ErbB-Dimerisierungsinhibitor - Multi-Tyrosinkinase-

Inhibitoren · ErbB2-Immunkonjugat-Therapie

\section{Zusammenfassung}

Trotz der Erfolge individualisierter, zielgerichteter Therapien in der Behandlung von Patientinnen mit Mammakarzinom mit den derzeit verfügbaren Substanzen gilt es nach wie vor, weitere Substanzen mit anderen Resistenzmechanismen zu entwickeln. Derzeit werden einige neue zielgerichtete Substanzen für Patientinnen mit ErbB2 (HER2)-positivem Mammakarzinom und Progression unter Trastuzumab und Lapatinib in klinischen Studien untersucht. Die meisten dieser Substanzen sind monoklonale Antikörper und so genannte Multi-TyrosinkinaseInhibitoren. Den Daten aktuell publizierter Studien zufolge gibt es synergistische Effekte einiger neuer Substanzen, die zukünftig eine chemotherapiefreie Behandlung in der metastasierten Situation ermöglichen könnten.

complex as shown by the sustained inhibition of phosphorylation after withdrawal of the drug from the medium and confirmed by direct labeling of ErbB2 by [14C]HKI-272.

An open-label, 2-arm phase II trial conducted by Burstein et al. [3] evaluated the safety and efficacy of a daily 240-mg oral dose of neratinib in 136 women diagnosed with ErbB2positive locally advanced or metastatic breast cancer (stage IIIB, IIIC, or IV). Women enrolled in arm A $(\mathrm{n}=66)$ had either previously received at least 6 weeks of standard trastuzumab treatment or had experienced disease progression during or following trastuzumab-containing adjuvant therapy. Women in arm B $(\mathrm{n}=70)$ have had no prior treatment with

\begin{tabular}{ll}
\hline KARGER & ( ) 2010 S. Karger GmbH, Freiburg \\
Fax +497614520714 & Accessible online at: \\
Information@Karger.de & www.karger.com/brc \\
www.karger.com &
\end{tabular}


any ErbB2-targeted therapy, including trastuzumab. The efficacy analysis encompassed 127 evaluable patients, 61 in arm A and 66 in arm B. In participants who were previously treated with trastuzumab ( $\operatorname{arm} \mathrm{A}$ ), the progression-free survival (PFS) rate at 16 weeks was $60 \%$, and the median PFS was 23 weeks, as evaluated by independent assessment. The objective response and the clinical benefit rates were 26 and $36 \%$, respectively. Adverse events of any grade occurring in more than $15 \%$ of study patients included diarrhea, nausea, vomiting, fatigue, anorexia, abdominal pain, headache, and rash.

Neratinib is now being investigated in a randomized, double-blind, placebo-controlled phase III trial (Evaluating the Effects of Neratinib in Women with Early Stage Breast Cancer; ExteNET). Disease-free survival was defined as primary outcome, estimated enrollment will encompass 3,850 women with early-stage, ErbB2-positive breast cancer. The study started in July 2009, and is currently recruiting participants.

\section{Pertuzumab}

Pertuzumab is a recombinant, humanized monoclonal antibody that binds to the extracellular domain II, sterically blocking homo- and heterodimerization with other ErbB receptors, thus preventing signal transduction. Pertuzumab inhibits the formation of the ErbB2 heterodimer. Its activity is thought to be independent of ErbB2 expression levels, and its binding site does not overlap with the epitope on ErbB2 that is recognized by trastuzumab. Given this activity, pertuzumab represents an ErbB dimerization inhibitor $[4,5]$.

Based on the promising results of phase I studies, Gelmon et al. [6] evaluated the efficacy and safety of pertuzumab and trastuzumab in a phase II study in patients with ErbB2-positive metastatic breast cancer, who progressed during prior trastuzumab therapy $[5,6]$. Patients received trastuzumab at either $4 \mathrm{mg} / \mathrm{kg}$ loading dose (LD) followed by $2 \mathrm{mg} / \mathrm{kg}$ once weekly or $8 \mathrm{mg} / \mathrm{kg} \mathrm{LD}$, followed by $6 \mathrm{mg} / \mathrm{kg}$ every 3 weeks (q3w). Pertuzumab was given at a loading dose of $840 \mathrm{mg}$, followed by $420 \mathrm{mg}$ q3w; 21/66 women remained on therapy. Of the $16 / 66$ patients $(24 \%)$ who responded to therapy, 5 had complete (CR) and 11 partial responses (PR); another 17 patients had stable disease for 6 months, for a total of $33 / 66$ $(50 \%)$ receiving clinical benefit. Most frequent events included diarrhea (64\%), fatigue (33\%), nausea (27\%), and $\operatorname{rash}(26 \%)$.

Suggesting potential antitumor activity of pertuzumab in combination with trastuzumab in patients who are refractory to trastuzumab prompted the initiation of the randomized, double-blind, placebo-controlled, multicenter international phase III CLEOPATRA (CLinical Evaluation Of Pertuzumab And TRAstuzumab) study which is currently recruiting participants (fig. 1). The primary objective of the study, which will enroll 800 patients, is to compare PFS rates in patients randomized in a one-to-one fashion to either trastuzumab

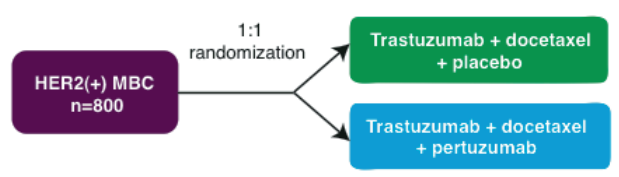

An international Phase III randomized, double-blind, placebo-controlled study (approximately 250 sites worldwide) Enrollment stratified: Endpoints:

- Prior treatment for breast cancer $\quad$ Progression-free and overall survival - Geographical region of enrollment $\quad$ Quality of life - Biomarker analysis

Fig. 1. Design of the CLEOPATRA trial.

plus docetaxel and placebo or trastuzumab plus docetaxel and pertuzumab. Women with ErbB2-positive metastatic breast cancer, who have not received chemotherapy or biologic therapy (including approved or investigational tyrosine kinase/ ErbB inhibitors or vaccines) for their metastatic disease, are eligible for the study. The study began recruiting patients in January 2008, and is projected to complete enrollment in 2010.

\section{Trastuzumab DM-1}

Direct covalent coupling of cytotoxic agents to monoclonal antibodies is an alternative to naked antibody-targeted therapy. To date, antitumor antibodies have been linked to cytotoxic agents, such as the calicheamicins, auristatins, maytansinoids, and derivatives of CC1065 [7]. Since ErbB2 is highly differentially expressed on breast tumor cells compared with normal epithelial cells, ErbB2 represents an ideal target for antibody-drug conjugate (ADC) therapy.

Maytansinoids are derivatives of the antimitotic drug maytansine, binding directly to microtubules in a manner similar to the vinca alkaloids [8]. Numerous preclinical and clinical studies indicate that trastuzumab combines well with microtubule-directed agents like maytansinoids [9]. Given the mechanism of action and the potency of maytansine, it was deemed to be a particularly attractive cytotoxic agent to conjugate to trastuzumab in order to circumvent the problem of resistance. Trastuzumab is combined with DM1 (T-DM1), an anti-microtubule agent derived from maytansine [9], and is an ErbB2 ADC. In a first-in-human phase I study, Beeram et al. [9] evaluated the safety and pharmacokinetics of T-DM1 given intravenously (IV) $\mathrm{q} 3 \mathrm{w}$ in 24 patients with ErbB2positive metastatic breast cancer who have progressed on a trastuzumab-containing regimen. Women received 156 doses of T-DM1 at 6 different dose levels: $0.3 \mathrm{mg} / \mathrm{kg}, 0.6 \mathrm{mg} / \mathrm{kg}$, $1.2 \mathrm{mg} / \mathrm{kg}, 2.4 \mathrm{mg} / \mathrm{kg}, 3.6 \mathrm{mg} / \mathrm{kg}$, and $4.8 \mathrm{mg} / \mathrm{kg}$ administered IV q3w. Six of 16 patients dosed at $2.4 \mathrm{mg} / \mathrm{kg}$ and $3.6 \mathrm{mg} / \mathrm{kg}$ achieved a PR, and another 5 patients achieved stable disease continuing after 130-260 days. Adverse events included transaminase elevations, thrombocytopenia, fatigue, anemia, 
Fig. 2. Design of the EMILIA trial.

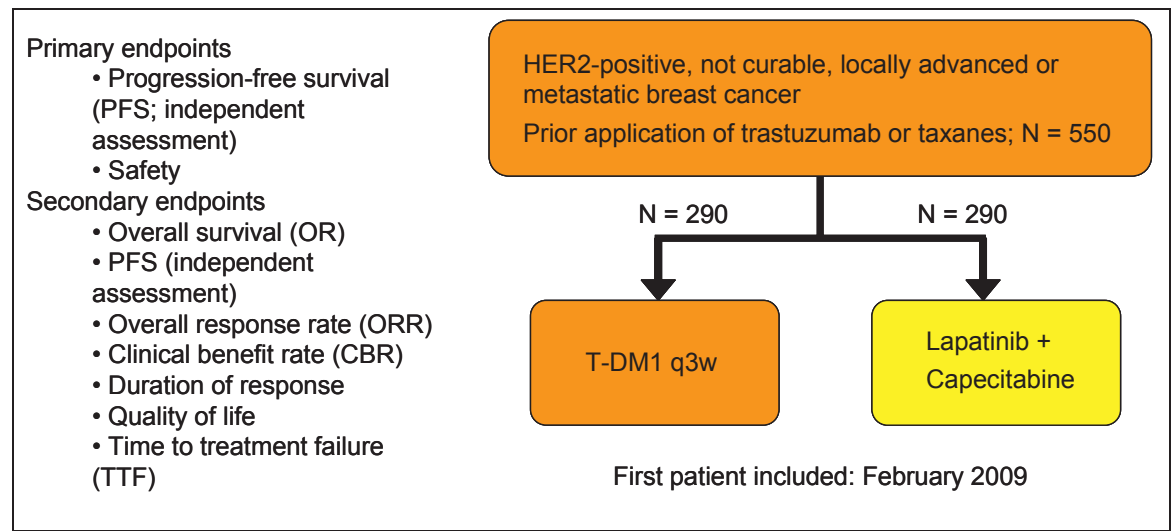

and neuropathy. Cardiac toxicity was not observed. It was concluded that the maximum tolerated dose and recommended dose for phase II trials should be $3.6 \mathrm{mg} / \mathrm{kg}$ IV q3w as it is a tolerable and manageable dosing schedule.

Vukelja et al. [10] presented the data of a multi-institutional, open-label, single-arm phase II trial, assessing the safety and clinical effectiveness of T-DM1 in patients who have progressed while receiving ErbB2-directed therapy and chemotherapy for ErbB2-positive metastatic breast cancer. A total of 112 women were enrolled and received T-DM1 at $3.6 \mathrm{mg} / \mathrm{kg}$ IV q3w. Out of the 86 patients with ErbB2 information, 64 were confirmed to be ErbB2-positive (74.4\%) either by fluorescence in situ hybridization (FISH) and/or immunohistochemistry $(\mathrm{IHC})+3$ ). The median follow-up was 4.4 months, and the median number of treatment cycles administered was $5(1-16+)$. The objective response rate (PR/CR) was $50 \%$ (32 of the 64 patients), and the confirmed response by the Independent Review Facility assessment accounted for $34.4 \%$ (22 of the 64 patients). Activity in lapatinib pretreated patients was consistent with the entire study population with an objective response rate of $38.3 \%$ and a confirmed overall response rate of $21.7 \%$. The most common severe (grade 3 or 4 ) adverse events were hypokalemia in $8 \%$ of patients and thrombocytopenia in $7 \%$. No severe (grade 3 or 4 ) cardiacspecific toxicity was observed.

A global, randomized, multicenter, 2-arm, open-label phase III study (EMILIA) was initiated in February 2009, comparing the safety and efficacy of second-line single agent T-DM1 with that of lapatinib plus capecitabine for women with ErbB2-positive metastatic breast cancer (fig. 2). A total of 580 patients will be enrolled at approximately 260 sites worldwide. Primary outcome parameters are PFS as well as the incidence, nature, and severity of adverse events.

\section{Disclosure Statement}

The author was a speaker and contributor to the meeting 'ErbB2 (HER2)-positives Mammakarzinom; 2. Münchner Brustkrebs-Symposium Update 2009', 23-24 October 2009 in Munich, sponsored by GlaxoSmithKline.

\section{References}

1 Sequist L: Second-generation epidermal growth factor receptor tyrosine kinase inhibitors in nonsmall cell lung cancer. Oncologist 2007;3:325-330.

-2 Rabindran SK, Discafani CM, Rosfjord EC, et al.: Antitumor activity of HKI-272, an orally active, irreversible inhibitor of the HER-2 tyrosine kinase. Cancer Res 2004;64:3958-3965.

3 Burstein HJ, Sun Y, Tan AR, et al.: Neratinib (HKI-272), an irreversible pan ErbB receptor tyrosine kinase inhibitor: phase 2 results in patients with advanced HER2+ breast cancer. 31st Annual San Antonio Breast Cancer Symposium 2008; abstr 37.

4 Agus DB, Akita RW, Fox WD, et al.: Targeting ligand-activated ErbB2 signaling inhibits breast and prostate tumor growth. Cancer Cell 2002;2:127137.
5 Baselga J, Imadalou K, Paton V, Gray D, Swain S: Efficacy, safety and tolerability of dual monoclonal antibody therapy with pertuzumab + trastuzumab in HER2+ metastatic breast cancer patients previously treated with trastuzumab. Annual San Antonio Breast Cancer Symposium 2008; poster 3138.

6 Gelmon K, Furnoleau P, Verma S, Wardley A, et al.: Results of a phase II trial of trastuzumab and pertuzumab in patients with HER2 positive metastatic breast cancer who had progressed during trastuzumab therapy. J Clin Oncol 2008; 26(suppl):abstr 1026.

7 Lewis Phillips GD, Li G, Dugger DL, et al.: Targeting HER2-positive breast cancer with trastuzumabDM1, an antibody-cytotoxic drug conjugate. Cancer Res 2008;68:9280-9290.
8 Chari RV, Martell BA, Gross JL, et al.: Immunoconjugates containing novel maytansinoids: promising anticancer drugs. Cancer Res 1992;52:127-131.

9 Beeram M, Burris H, Modi S, Birkner M, et al.: A phase I study of trastuzumab-DM-1, a first in class HER2 antibody-drug conjugate, in patients with advanced HER2+ breast cancer. ASCO Ann Meet Proc (post-meeting ed), J Clin Oncol 2007; 25(suppl):1042.

10 Vukelja S, Rugo H, Vogel C, et al.: A phase II study of trastuzumab-DM1, a first-in-class HER2 antibody-drug conjugate, in patients with HER2+ metastatic breast cancer. San Antonio Breast Cancer Symposium 2008;abstr 33. 